2018

\title{
Training Student Workers for Cross-Departmental Success in an Academic Library: A New Model
}

Kindra Becker-Redd

Fordham University

Kirsten Lee

Fordham University, bkilee@fordham.edu

Caroline Skelton

Fordham University

Follow this and additional works at: https://fordham.bepress.com/lib_staffpubs

Part of the Library and Information Science Commons

\section{Recommended Citation}

Becker-Redd, Kindra; Lee, Kirsten; and Skelton, Caroline, "Training Student Workers for Cross-Departmental Success in an Academic Library: A New Model" (2018). Library Staff Publications. 2.

https://fordham.bepress.com/lib_staffpubs/2 


\title{
Training Student Workers for Cross-Departmental Success in an Academic Library: A New Model
}

\author{
Kindra Becker-Redd, Kirsten Lee \& Caroline Skelton
}

To cite this article: Kindra Becker-Redd, Kirsten Lee \& Caroline Skelton (2018): Training Student Workers for Cross-Departmental Success in an Academic Library: A New Model, Journal of Library Administration, DOI: 10.1080/01930826.2017.1412711

To link to this article: https://doi.org/10.1080/01930826.2017.1412711

$$
\text { 曲 Published online: 03 Jan } 2018 .
$$

Submit your article to this journal

Q View related articles $₫$

View Crossmark data $\pi$ 


\title{
Training Student Workers for Cross-Departmental Success in an Academic Library: A New Model
}

\author{
KINDRA BECKER-REDD \\ Reference and Instructional Services Librarian, Quinn Library, Fordham University, \\ New York, NY, USA \\ KIRSTEN LEE \\ Intercampus and Interlibrary Loan Support Staff, Quinn Library, Fordham University, \\ New York, NY, USA \\ CAROLINE SKELTON \\ Circulation and Reserves Support Staff, Quinn Library, Fordham University, \\ New York, NY, USA
}

\begin{abstract}
Many academic libraries rely on a student workforce for everyday operations, interacting with patrons, and assistance with larger projects. Training these students for such multifaceted and customer-service-focused positions can be a challenge. This article traces an overhaul of training procedures made during the transition to a centralized, services desk workflow. All aspects of training a large student workforce, from planning and presentation to assessment, are outlined. Interactive group sessions and peer-to-peer reinforcement of procedures have proven to be most effective in training student workers for varied roles in an academic library.
\end{abstract}

KEYWORDS student workers, student library assistants, job training, training, student training, academic library, universities, colleges, Fordham University, scheduling, work-study students, library training, training of student employees, assessment, staffing, mentoring, student employment

(c) Kindra Becker-Redd, Kirsten Lee, and Caroline Skelton

Address correspondence to Kindra Becker-Redd, Reference and Instructional Services Librarian, Quinn Library, Fordham University, 140 West 62nd Street, New York, NY 10023, USA. E-mail: kbeckerredd@fordham.edu 


\section{INTRODUCTION}

Student workers at the Gerald M. Quinn Library of Fordham University play a vital role in the daily management of library operations. All library staff at Quinn rely on student workers to interact with patrons and help oversee this busy campus library. In addition to shelving, shelf reading, and stacksrelated projects, student workers are responsible for a wide range of tasks including general circulation, basic technology assistance, and the circulation of reserve material. Once students are assigned to the library for work-study by Fordham's Student Employment Office, library staff trains and manages the student workers. With a full-time staff of 12, training a student staff of 40 can be daunting.

This article will address the authors' overhaul of the existing studentworker training program during the summer of 2016 and its implementation in the following fall academic semester. The new program targets the changing role of student workers in an academic library, the variety of training methods used for young employees, and the challenges faced with continued engagement and retention of such workers. The planning, format, and assessment of the training are discussed for both the initial training in September 2016 and the follow-up training sessions in January 2017. Final recommendations are made for any academic library seeking to evaluate and expand their training sessions to make the most of the undergraduate student workforce.

\section{BACKGROUND}

Fordham University is a Jesuit institution in New York, New York, with campuses in the Bronx, Manhattan, and Westchester counties. The Manhattan campus, located adjacent to Lincoln Center, has a total of 7,858 undergraduate and graduate students (Fordham University Facts, 2017). The Gerald M. Quinn Library serves the entire undergraduate and continuing education population at the Lincoln Center campus as well as graduate students pursuing degrees in business, education, and social work. All library student workers are undergraduate students employed through a federal work-study program. Fordham University's Student Employment Office accepts eligible applications, interviews students, and places students at Quinn Library. Typically, Student Employment assigns between 36 and 42 students to Quinn, and these student workers reflect a wide diversity of cultures, religions, and backgrounds.

Throughout Quinn Library's history, student worker training has taken on many iterations. Several years ago, library administration developed 
modules to help orient and train students. This system consisted of individual documents that contained step-by-step instructions on circulation, stack maintenance, reference, technical support, book repair, and preservation, reserves, the audiovisual department, and timeclock procedures. Outside links, such as Kent State University Libraries' Library of Congress Call Number Tutorial, and staff-produced training videos, were added later. All the materials were stored in the electronic reserve system and password protected.

At the beginning of each semester, new students submitted their schedules to a supervisor. Students were required to check in with a staff member who would then log into the electronic reserve system and instruct the student to read through the modules and complete all tasks. New student workers would shadow returning student workers during shelving and other stacks and circulation projects. Total training time was approximately 3 hours, providing students read through all the required material and then shelved a cart of books. The only system in place for confirming that students performed all parts of the training was a checklist kept in their supervisor's files. Returning student workers did not receive instruction after their first semester at Quinn; rather, they were asked to review modules as staff noticed a need.

In 2015, staff noticed that often students' work schedules did not correspond to the amount of library tasks at hand. During certain times of the day, no student workers would be available, and at other times there would be more student workers than actual work. Students would become frustrated when they arrived to find there were no seats available at the service desks or there was an absence of stacks projects. Staff observed that studentworker training was spotty and ineffective. Furthermore, it was noted that some students only did a few modules in the beginning of their freshman year, while others never looked at them. Some staff would work individually to train workers, but this could not be done for all new students. Some students were able to handle all responsibilities proficiently, while others could handle only basic circulation tasks. Generally, staff were frustrated, and students were confused; a more organized method was needed to make the best use of the student workers' time.

Quinn Library's move to a brand new facility on campus in 2016 initiated many conversations around service models and customer service expectations; the library was shifting from separate reference and circulation desks to a one-stop library services desk. Both staff and student workers would have to adjust to a more cross-departmental outlook on library services. As Quinn Library began preparations for the move, staff saw an opportunity to reinvigorate student worker training not only to reflect the new cross-departmental space but also to fill the gaps in training left by the older model. 


\section{LITERATURE REVIEW}

\section{Role of Student Workers in an Academic Library}

As budgets decrease and staffing is cut, academic libraries are relying on student workers to fulfill many of the day-to-day operations once done by full-time and part-time support staff (Ireland \& Jackson, 2015). According to observation, circulation transactions, fielding routine reference questions, assisting with technology, and providing customer service are the most common roles executed. Additionally, much of the work students conduct involves rescuing librarians from the more monotonous, repetitive, and tedious tasks for which they have little time (McGinniss \& Michael, 2013). These general departmental descriptions are somewhat limiting, as depending on the individual, they may do more or less than what is required of them. As R. Lowery states in a personal interview, "it is difficult to provide an exact job description for students who work with me because students who work here bring more of themselves to the job that allows me to make use of their skills" (Logan, 2012, p. 320). When library staff work with individual students, they can determine what responsibilities each student can handle. A survey by the Louisiana Academic Libraries by Ireland and Jackson (2015) examined the tasks assigned to student workers across 23 campuses. The responses ranged from the usual shelving and circulation tasks to more complex assignments such as assisting with digitization projects, basic catalogue maintenance, and book repair.

Although employing student workers is often financially necessary, some libraries bemoan the fact that it has become expected to give these students positions, no matter their qualifications or work ethic (Gerlich, 2002). Given the variety of work experience, scheduling and course loads of these students, providing strong and consistent training is paramount to maintaining competent and engaged student workers.

\section{Training Methods}

Training methods for student workers vary dramatically from department to department and institution to institution. While goals for this type of training depend greatly on the specific department and type of work, overall the research suggests that training begins with supervisors' intentions. Managers should set clear expectations for students and repeatedly communicate those expectations (McGinnis \& Michael, 2013). Drewitz (2013) also suggests that managers take the time to consider "what type of supervisor you will be" (p. 23) and then to spend meaningful time training students, rewarding good behavior, and promptly addressing negative performance.

To plan training for students, Leuzinger (2011) researched different styles of learning-visual, auditory, and kinesthetic-and designed 
components of the training to address each style. Additionally, Leuzinger developed a student handbook and trained large groups of students by giving tours, hosting several group training sessions, and pairing returning student workers with new student workers. This method allowed the department to cover all the necessary material while continuing training beyond the group sessions. With small groups of students, Manley and Holley (2014) found that demonstration videos and voice over PowerPoints worked well when combined with shadowing full-time staff. Vassady, Archer, and Ackermann (2015) trained students to work at the reference desk by requiring them to read a student manual, to attend group training sessions (featuring games and question and answer sessions), and to participate in monthly meetings. Additionally, Vassady, Archer, and Ackermann (2015) had the flexibility to give student workers in the department annual performance reviews. Both students and supervisors were provided a checklist for training so that all involved would know the expectations set for the student workers.

Though often the hiring of student workers is outside of the library's or department's control (McGinnis \& Michael, 2012), it is important to remember that not only are students the face of the library but also the professionalism instilled in student workers will carry on into the work force (Drewitz, 2013).

\section{Continued Engagement and Encouragement}

In the opinion of Quinn Library's staff, the key to maintaining a community of student workers connected to the overall goals of the institution lies in the continued encouragement of and engagement with these employees. These two approaches have been discussed in terms of motivation and participatory cultures. Reales (2013) considers a lack of motivation in student workers to be rooted in anxiety and confusion. It is the role of supervisors to "model motivation" and, through displaying an active interest in and appreciation of the students, to help them understand the extent of their contributions to the library (Reales, 2013). Charles, Lotts, and Todorinova (2017), assessed the impact of library employment on undergraduate students with the goal of further integrating them into the institution. Their results noted disconnect between the lack of perceived benefits to their employment and their value to the organization; therefore, as libraries strive to demonstrate value to their communities, supervisors must make sure to communicate this value to student employees (Charles, Lotts, \& Todorinova 2017). In addition, as with any encouragement protocol of student workers, flexibility of work schedules and instant recognition of a job well done has proven to be successful (Smith \& Galbraith, 2012). 


\section{FALL 2016 TRAINING}

\section{Proposal}

As part of a general re-evaluation of workflow needed to transition into the new Quinn facility, the authors formed a task force in June 2016 to evaluate student-worker functions. The task force identified issues with studentworker performance, including communication pathways, scheduling of student shifts, training sessions, and specific responsibilities necessary for each student-staffed area in the library. The student-worker scheduling system had been redesigned by two staff members earlier in the year and now provided specific assignments for students during each of their weekly work hours. After incorporating suggestions and edits from supervisors, the task force was prepared to implement the plan for the 2016-2017 academic year.

The finalized proposal called for several significant changes to student worker protocol, particularly in the area of training. The authors decided to implement new mandatory workshop sessions to replace the module form previously utilized. The task force approached student worker supervisors at the Rose Hill campus, but ultimately they decided to plan their own training programs.

\section{Schedule}

Three training sessions were offered on different days and times to accommodate as many schedules as possible. The sessions were scheduled for weekdays after students finalized their course schedules. Workshop times were staggered to allow students the most varied times to attend. Before the fall semester began, an email was sent from a new corporate email account devoted to student-worker communication to welcome and inform them of new expectations. To help ensure attendance, students were notified that they would not be allowed to submit work schedules or begin work until they completed a training session.

During planning, the task force decided to use Google Forms to track student responses and attendance. The August email also included a link to a training orientation survey, where staff gathered information about which orientation session all new and returning students would be attending. The overall response to the orientation survey was positive, with 39 responses received from 44 surveys sent (88.6\% response). The survey had a space for any additional notes or areas of training where a refresher was needed. The task force decided during planning that every form the Quinn Library staff sends to student workers will include an area to submit questions, comments, or concerns, because the staff recognizes that they will not think of everything that could or should be discussed. Three students (6.8\%) responded with training suggestions in this section. From these responses the 


\begin{tabular}{|c|c|}
\hline $\begin{array}{l}\text { 1. Student Worker Policies } \\
\text { - Internal behavior policies } \\
\text { - Scheduling framework } \\
\text { - Timesheet submissions and deadlines } \\
\text { 2. Tour of Library Facilities } \\
\text { 3. Customer Service } \\
\text { - Quinn Library user groups } \\
\text { - Basic do's and don'ts } \\
\text { - Phone etiquette } \\
\text { 4. Library of Congress Classification System } \\
\text { - Stacks projects and expectations } \\
\text { - Call number explanation and interactive } \\
\text { game }\end{array}$ & $\begin{array}{l}\text { 5. Circulation Policies and Tasks } \\
\text { - Basic circulation policies for items } \\
\text { and user groups } \\
\text { - Introduction to the library website } \\
\text { - Circulation functions in SIRSI } \\
\text { 6. Reserves Policies and Tasks } \\
\text { - Basic policies for reserve items } \\
\text { - Reserve functions in SIRSI } \\
\text { - Digital course reserve system } \\
\text { 7. Library Technology } \\
\text { - Printing instructions and issues } \\
\text { - Troubleshooting library machines }\end{array}$ \\
\hline
\end{tabular}

FIGURE 1 Quinn Library student worker training sequence. An outline of the topics covered during the Fall 2016 student worker training sessions.

staff was able to anticipate the attendance for each training session and the numbers of returning student workers as compared to new student workers.

\section{Format}

The design of the training was set by the authors during their work as the task force. The workshops incorporated PowerPoint presentations, roleplaying activities, and snacks to make the sessions more engaging and dynamic. The authors' goal was to deliver the most necessary information to students in a memorable way that would encourage them to seek out staff with more detailed questions.

Several staff members collaborated to design training presentations covering policies, customer service, circulation and reserve tasks, and technological issues (see Figure 1). These five topics were offered in the same order at each training session. The presentation of each section was given by the authors and other involved staff. The 10-minute break in the middle allowed students to relax and have a snack before resuming training. The authors recognize that the density of the material and the high expectations of staff can be overwhelming for students. It was important to provide food, a break, and interactive presentation techniques to keep the tone light and inviting.

\section{Training Assessment}

Two short quizzes were sent out, using Google Forms, to all attendees at the end of each training session. These forms served as a way for the staff to confirm attendance at the workshops and to gauge retention on significant issues. The first quiz consisted of five questions regarding call numbers and technology. Approximately half $(51.2 \%)$ of the student workers completed 
the quiz. Approximately $95 \%$ of these students answered all five questions correctly. The second quiz consisted of five questions regarding circulation and reserves policies and procedures. Just over half of the student workers (55.5\%) completed this quiz. Approximately $60 \%$ of these students answered all five questions correctly. All answers were received soon after the end of the training sessions, and no further requests were made of students who failed to submit responses.

The attendance rate of the mandatory training sessions was $97.5 \%$, as only one student worker hired at the time of the sessions was unable to attend any of the training workshops. This turn-out was higher than the workshop designers had expected, and all staff were very pleased with this attendance.

Student workers were sent a survey in November 2016 to reflect on the effectiveness of training. Of the 41 students surveyed, 32 responded for a response rate of $78 \%$. The survey asked students to rate the overall effectiveness of the training sessions on a scale from one to five, one being "I don't remember anything" and five being "I learned so much" (see Figure 2a). The survey also asked students to rate how enjoyable the training sessions were, on a scale from one to five, one being "Soooo boring" and five being "Non-stop thrill ride" (see Figure $2 \mathrm{~b}$ ).

The authors were pleased to see that most students remembered the training sessions as relatively effective and enjoyable. While the higher number of mediocre responses to the enjoyability of the sessions is not surprising, it indicates an area for development in subsequent training activities.

\section{Follow-Up Training}

At the end of the Fall semester, staff began planning a training session designed to refresh students on policies and procedures. These instructions

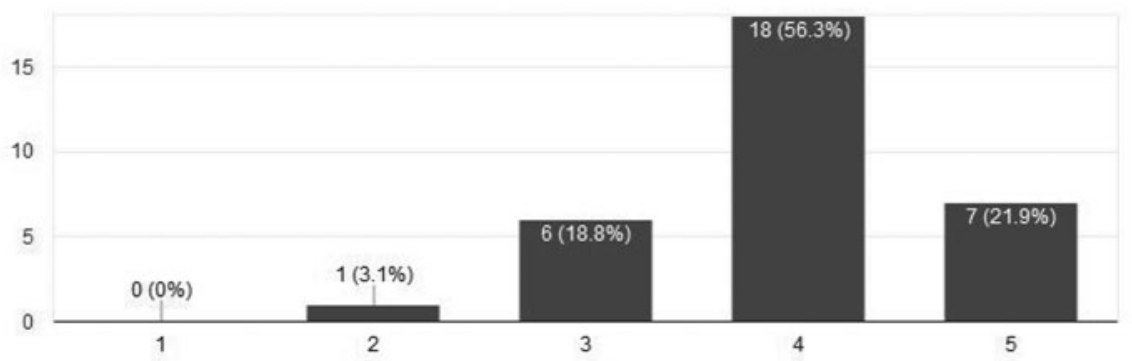

FIGURE 2a Student worker training survey effectiveness results. The results of the Quinn Library training survey taken in November 2016, ranking from 1 to 5, with 5 being the most effective. 


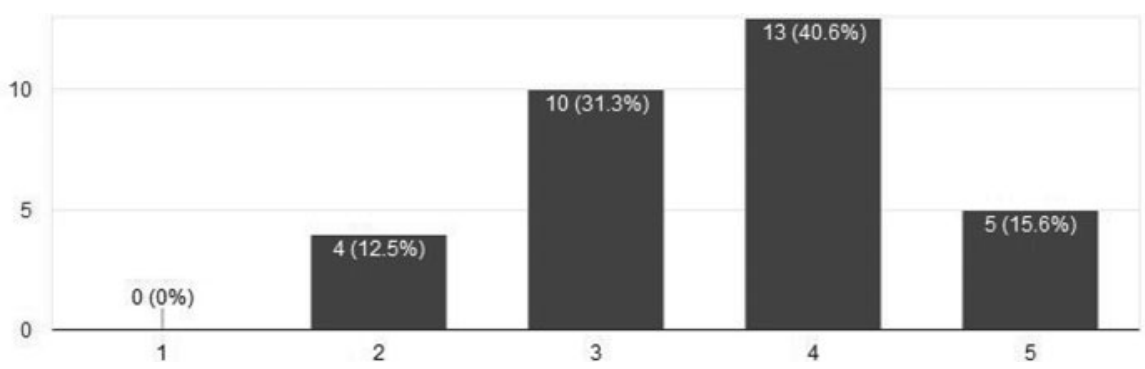

FIGURE 2b Student worker training survey enjoyability results. The results of the Quinn Library training survey taken in November 2016, ranking from 1 to 5 , with 5 being the most enjoyable.

were scheduled for the beginning of the Spring 2017 semester, and students were polled to determine best times. All students were required to attend the review sessions but were able to begin working before their scheduled session. Based on staff observation, student workers needed reminders of tasks and procedures after the winter recess. This review program had two main functions: updating student workers on new policies and procedures and, secondly, re-training student workers in areas that were deemed necessary. The subjects that staff decided to address were determined by asking them to recommend topics where they noticed student workers having difficulty and by polling the student workers about areas in which they felt a need for additional support. A Google Form was created and distributed to student workers in November 2016. The form asked student workers to reflect on their experience with the training sessions held in September and to identify subjects that they felt needed clarification. Results are shown in Figure 3. Feedback from staff members was gathered informally.

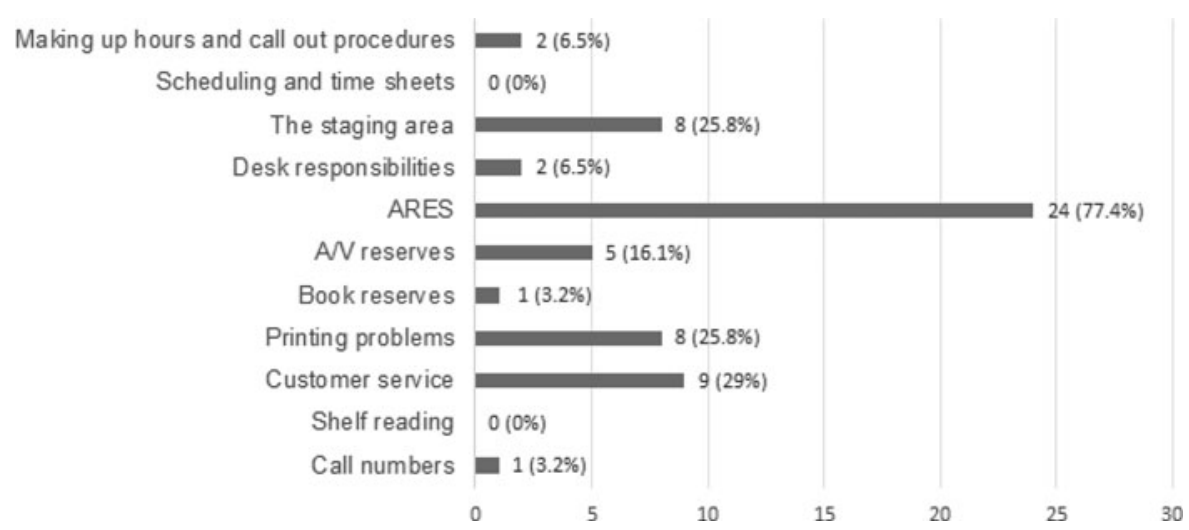

FIGURE 3 Student worker training survey refresh results. The results of the Quinn Library training survey taken in November 2016, asking student workers to reflect upon which content they felt they needed additional training. 


\section{Topics and Format}

Both student workers and staff contributed ideas as to what to cover during the refresher training. Student workers were sent the training survey in November and were able to comment directly on the signup form in January. Eleven student workers responded to the comment section of the signup form with recommended topics. The comments from this form and the previous survey saw a similar trend in topics that needed clarification, the highest percentage asking about course reserves, audio/visual materials, customer service, and technical support.

Staff reviewed student-worker policies, Library of Congress call numbers, the book receiving-room functions, and phone procedures. From these topics, the authors built the agenda shown in Figure 4.

All of the outlined material was covered in one hour, with the majority of student workers attending the entire presentation. Participation was encouraged, with student workers following along in tutorials on the classroom computers. The telecommunications department set up two "dummy phones" in the classroom so that student workers could practice placing calls on hold and transferring calls. Students who did not attend were required to make an appointment with their supervisor before their next shift to go over what they missed.

\section{CONCLUSION}

\section{Overall Assessment}

With the completion of both the Fall 2016 semester and the follow-up training in late January 2017 , library staff have had several months to observe the long-term effectiveness of the newly developed training protocols. Effectiveness in this context is measured as an increase in adherence to student worker policies, greater retention of relevant skills and information, and a marked consistency in overall student-worker performance over time. Staff were provided with a Survey of Student Worker Effectiveness to afford a means of unbiased assessment. Shown in the Likert scales in the Figures $5 \mathrm{a}$ and 5b, the majority of staff responded that they "Agreed" or "Strongly Agreed" that student-worker effectiveness improved following both training sessions.

\begin{tabular}{|l|l|}
\hline 1. Policies & 5. Phone Use and Customer Service \\
2. New Information & 6. Reserves Review \\
3. Call Number Review & 7. Targeted Library Tour \\
4. Reference Review & \\
\hline
\end{tabular}

FIGURE 4 Quinn Library student worker refresher training schedule. An outline of the topics covered during the Spring 2017 student worker refresher training sessions. 


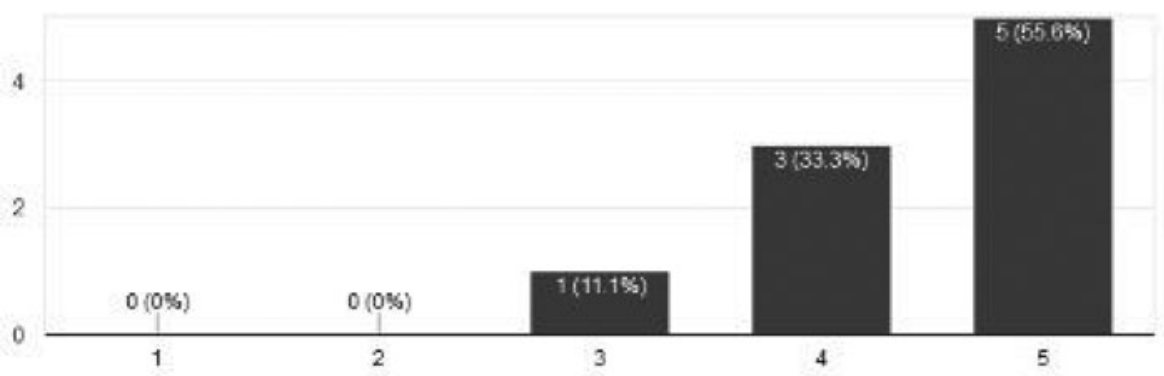

FIGURE 5a Quinn Library staff survey. Results of the survey sent to Quinn Library staff members about the effectiveness of student workers from Spring 2016-Fall 2016, ranking from 1 to 5 , with 5 being the most improvement.

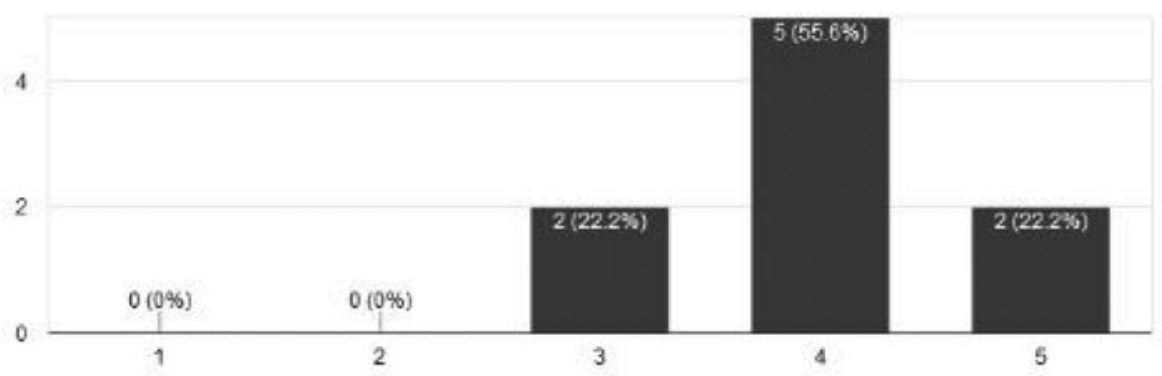

FIGURE 5b Quinn Library staff survey. Results of the survey sent to Quinn Library staff members about the effectiveness of student workers from Fall 2016-Spring 2017, ranking from 1 to 5 , with 5 being the most improvement.

Although metrics are not available in all relevant areas, the surveys contain additional data pertaining to the effectiveness of training in the areas of circulation, reserves, technology, stacks, and customer service. As similarly noted in the previous two charts, the majority of staff "Agreed" or "Strongly Agreed" that student worker effectiveness had improved in all areas.

\section{Future Plans and Recommendations}

Staff involved in the development and implementation of the newly developed training protocols have expressed positive reactions towards their involvement with this process and will continue to refine the training content, training process, retention training methods, and means of effectiveness assessment for future semesters.

The authors will conduct training sessions for all new and returning student workers at the beginning of the Fall 2017 semester. The training will be done in two, 2 hour blocks. The first session will cover circulation policies and procedures, customer service, and the Library of Congress classification 
system. The second session will cover reference, reserve policies and procedures, and technology assistance. All student workers will be required to complete both training sessions. Efforts will be made to incorporate more interactive training exercises to replace some aspects of the PowerPoint presentations.

New and returning student workers will be paired as "buddies" during the training sessions. This will provide returning students with some autonomy and responsibility to share their knowledge with their peers. The training sessions will utilize peer-to-peer training for procedures pertaining to the circulation, reserve, and stacks departments. This "buddy" system will be maintained for the fall semester to encourage new student workers to learn from their peers. The authors hope that this structure will give returning students more confidence in their roles at Quinn Library and lead to stronger working relationships among all students.

Academic libraries looking to update their student-worker training methods have many variables to consider. Supervisors need to think about goals and expectations for themselves and their students and critically examine their roles and what that entails beyond the jobs that need to get done. When deciding on a training format, it is necessary to determine how much time staff can commit to training. Factoring in student interests and needs can go a long way in narrowing down what will work for each specific department. It is important to consider the number of students employed in the library; for example, it may be easier to train a small number of student workers one on one, or build a small batch of modules that are easy to update from year to year. For a larger group of students, it is essential to evaluate the most efficient way to communicate necessary and important information, remembering that in large training sessions staff cannot cover every aspect of all topics. Expanding research beyond libraries, thinking about effective training at other jobs in different industries, and polling staff about training methods they have encountered and disliked are all constructive ways to prepare a new training regimen. Finally, remember that whatever is built will be unique to that library's culture.

Ultimately, student workers are invaluable additions to any library, both for the work they do and for their energy and personality. However, they are students first, employees second. The supervisor's job is to give student workers the information and skills they need to succeed at work but also to give them the flexibility to focus on school. Only by providing the right foundation to students can that job really begin.

\section{ACKNOWLEDGMENTS}

The authors thank Robyn Ayers and Mike Magilligan for contributing materials and their time to the training sessions, Diane Batemarco and Diane 
Deery for their insightful feedback, Robert Allen and Linda LoSchiavo for supporting new ideas and supervising the project, and Nicholas Alongi for directing the training sessions and providing a framework for their development.

\section{References}

Charles, L. H., Lotts, M., \& Todorinova, L. (2017). A survey of the value of library employment to the undergraduate experience. Journal of Library Administration, 57(1), 1-16. doi:10.1080/01930826.2016.1251248

Drewitz, J. M. (2013, November). Training student workers: A win-win; mentoring student workers and improving customer service in your library. AALL Spectrum, 18(2), 23-24. Retrieved from www.aallnet.org/mainmenu/Publications/spectrum/Archives/Vol-18/No-2/student-workers.pdf

Gerlich, B. K. (2002). Rethinking the contributions of student employees to library services. Library Administration \& Management, 16(3), 146-150.

Fordham University. (2017). Fordham University Facts. Retrieved from https://www. fordham.edu/info/20088/fordham_facts

Ireland, S., \& Jackson, J. (2015). The shifting roles of student workers. In S. Hines \& M. Simons (Eds.), Advances in library administration and organization (Vol. 34, pp. 201-223). Bingley, UK: Emerald Group Publishing. doi:10.1108/S0732067120150000034009

Leuzinger, J. (2011). Connect with your part-time library staff: Using learning styles to individualize training. Texas Library Journal, 87(3), 78-80.

Logan, F. (2012). Student workers: Essential partners in the twentyfirst century academic library. Public Services Quarterly, 8(4), 316-325. doi:10.1080/15228959.2012.731838

Manley, L., \& Holley, R. P. (2014). Hiring and training work-study students: A case study. College \& Undergraduate Libraries, 21(1), 76-89. doi:10.1080/10691316.2014.877739

McGinniss, J., \& Michael, J. B. (2013, November 1). Our student library workers rock! Investing in the student staff development process. In F. Baudino \& C. Johnson (Eds.), Brick \& click libraries: An academic library symposium (13th ed., pp. 20-29, online submission). Retrieved from http://files.eric.ed.gov/fulltext/ED545375.pdf

Reales, M. (2013). Mentoring and managing students in the academic library. Chicago, IL: ALA Editions.

Smith, S. D., \& Galbraith, Q. (2012). Motivating millennials: Improving practices in recruiting, retaining, and motivating younger library staff. The Journal of Academic Librarianship, 38(3), 135-144. doi:10.1016/j.acalib.2012.02.008

Vassady, L., Archer, A., \& Ackermann, E. (2015). READ-ing our way to success: Using the READ Scale to successfully train reference student assistants in the referral model. Journal of Library Administration, 55(7), 535-548. doi:10.1080/01930826.2015.1076309 